\title{
DOUBLE DIFFUSIVE MIXED CONVECTION HEAT TRANSFER INSIDE A VENTED SQUARE CAVITY
}

\author{
Sumon Saha ${ }^{* 1}$, Mohammad Nasim Hasan ${ }^{2}$, Iftheker Ahmed Khan ${ }^{3}$ \\ ${ }^{1}$ Department of Mechanical Engineering, The University of Melbourne, Victoria-3010, Australia \\ ${ }^{2}$ Department of Mechanical Engineering, Saga University, 1 Honjo-machi, Saga 840-8502, Japan \\ ${ }^{3}$ Department of Civil E Environmental Engineering, University of South Carolina, Columbia, SC 29208, USA
}

Received 23 March 2009; received in revised form 1 September 2009

\begin{abstract}
A numerical study has been carried out for laminar double-diffusive mixed convection in a twodimensional vented square cavity with discrete heat and contaminant sources applied on the bottom wall. An external air flow enters the cavity through an opening located at the bottom of the left vertical wall and exits from an opening located at the three different positions of the opposite wall. The developed mathematical model is governed by the two-dimensional continuity, momentum, energy, and concentration equations. The governing equations, written in non-dimensional form are solved by using Galerkin finite element method with triangular grid discretization system. The Reynolds number is fixed at 100 and the working fluid is considered as air. Numerical simulations are carried out for different combinations of the thermal Grashof numbers and results are presented in terms of streamlines, temperature and concentration distributions. The results indicate that the average Nusselt and Sherwood numbers on the heat and contaminant sources strongly depend on the positioning of the exit opening.
\end{abstract}

Keywords: double diffusive mixed convection, vented cavity, finite element

DOI:10.3329/cerb.v13i1.2512

\section{Introduction}

Double diffusive mixed convection in cavities has been subject of an intensive research due to its importance in various engineering and geophysical problems. This includes nuclear reactors, solar ponds, lakes and reservoirs, solar collectors and crystal growth. Nowadays, control of indoor air environment is becoming a cutting-edge issue for study of double diffusive mixed convection in a ventilated room. Several discrete heat and contaminant sources, such as pets, cooking, smoking, burning furnace, blazing window, office automation equipments, and building materials and furnishings, which intermittently or continuously produce allergens, heat, gas components $\left(\mathrm{CO}_{2}, \mathrm{CO}, \mathrm{NO}_{x}\right)$, particulate matter $\left(\mathrm{PM}_{10}, \mathrm{PM}_{2.5}\right)$, and volatile organic compounds (VOCs) within a ventilated room $[1,2]$. There exist two different types of convection in a vented cavity; namely internal buoyancy-induced natural convection by the discrete heat and contaminant sources and external mechanical-driven forced convection by the ventilation. The fluid flow and heat or contaminant transfer characteristics inside the vented cavity are thus found by the interaction between the natural convection and the force one, which results in double diffusive mixed convection.

*Corresponding author Email: s.saha2@pgrad.unimelb.edu.au
A literature review concerning ventilated enclosures shows that some available works have considered the problem of mixed convection in rectangular cavities. Papanicolaou and Jaluria [3-7] carried out a series of numerical studies in order to investigate the combined forced and natural convective cooling of heatdissipating electronic components located in a rectangular enclosure, and cooled by an external throughflow of air. Laminar mixed convection in a twodimensional enclosure heated from one sidewall and submitted to an either aiding or opposing jet was numerically studied in the work of Angirasa [8] and Raji and Hasnaoui [9, 10]. Later, Raji and Hasnaoui [11] investigated the mixed convection in ventilated cavities where the horizontal top wall and the vertical left wall were prescribed with equal heat fluxes. Similar investigations were also carried out by the same authors taking into consideration the effect of the thermal radiation on mixed convection [12].

A numerical study of an enclosure with a heated vertical plate located in the cavity was carried out by Hsu and Ang [13]. Discrete heat sources were embedded on the plate and different orientations were considered. When the heat source was embedded on the surface of the board opposite to forced flow inlet; the value of the convective Nusselt number was found to be independent of the location of the heat source. Omri and Nasrallah [14]studied mixed con- 
vection in a rectangular enclosure with differentially heated vertical sidewalls having openings for inlet and outlet. Two different placement configurations of the inlet and outlet openings on the side walls were investigated. In the first case, the cold air was injected at the top of the hot wall and exited at the bottom of the cold wall, whereas in the second configuration the injection was at the lower edge of the hot wall and the exit was at the top of the cold wall. Improvement in cooling efficiency was found with the inlet placed at the bottom of the hot wall. Similar investigations were also carried out by Singh and Sharif [15] considering six placement configurations of the inlet and outlet openings. They observed that maximum cooling effectiveness was achieved if the inlet was kept near the bottom of the cold wall while the outlet was placed near the top of the hot wall. Recently Saha et al. [16] carried out similar numerical experiments for mixed convection in a vented enclosure with constant heat flux heating from below. Four different locations of inlet and outlet openings were introduced to analyze the effect of heat transfer mechanism and their results critically explained the importance of the orientation of the inlet and exit ports in a vented enclosure. Further investigations on the same topic were carried out by Saha et al. with the same geometric configurations but considering isoflux heating at the right sidewall [17].

The effects of combined thermal and solutal buoyancy induced by temperature and concentration gradients have, however, not been widely studied. Yan [18, 19] and Lee et al. [20] analyzed the transport phenomena of developing laminar mixed convection heat and mass transfer in rectangular ducts. Later, Alimi et al. [21] studied the buoyancy effects on mixed convection heat and mass transfer in an inclined duct preceded with a double step expansion. Brown and Lai [22] numerically examined combined heat and mass transfer from a horizontal channel with an open cavity heated from below. Since heat and contaminant sources usually co-exist indoors, the present work is to numerically study the double-diffusive mixed convection in a vented cavity due to the discrete heat and contaminant sources. As far as authors know, the problem has never been concerned in the public literatures until Deng et al. [23] performed a similar investigation of the similar problem inside a ventilated enclosure. However, a detailed investigation is still deserved to understand the effect of exit port location on the indoor air environment. Therefore, the objective of the present work is to investigate the new characteristics of the airflow and heat/contaminant transport mechanism inside a vented cavity in terms of streamlines, isotherms and isoconcentration lines.

\section{Analysis}

\subsection{Physical Model}

The domain under analysis is, as sketched in Figure 1, a square two-dimensional cavity, suffering the influence of a gravitational field. An isoflux heat source, q of size $\mathrm{L}_{s}$ and a contaminant source of equal size and high concentration $c_{h}$ locate on the right part of the bottom wall. The remaining top, bottom and sidewalls are assumed to be adiabatic and impermeable. The inflow opening of size $d$ is located on the lower left vertical wall while the location of the equal size outflow opening is varied in three different arrangements of the right vertical wall as shown in Figure 1 (a), (b) and (c). Low speed fresh cold air $\left(\mathrm{u}_{i}, \mathrm{~T}_{i}, \mathrm{c}_{i}\right)$ is injected through the inlet opening in the horizontal direction and then the polluted hot air exhausted from the outlet opening at the right side wall. Hence the outflow is assumed to have zero diffusion flux for all variables (outflow boundary condition [OBC]).

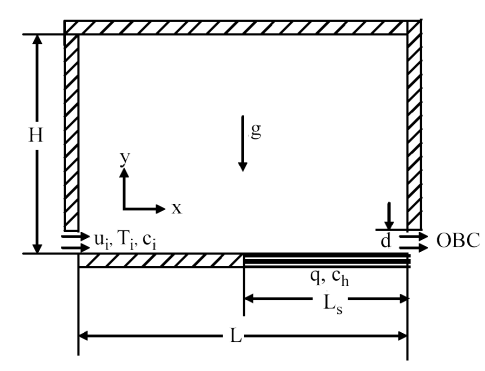

(a) bottom exit configuration

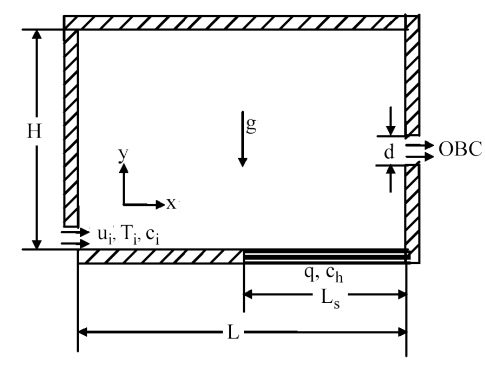

(b) middle exit configuration

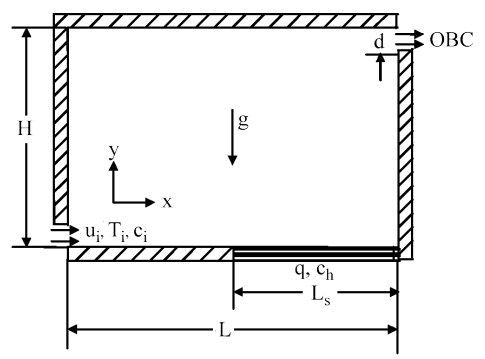

(c) top exit configuration

Figure 1: Schematic diagram for the problem with boundary condition 


\subsection{Mathematical Model}

The governing mass, momentum, energy and species conservation equations have been presented by Deng et al. [23] for double-diffusive mixed convective flows driven by the combined effect of the internal buoyancy induced from temperature and concentration differences and the external mechanicaldriven forced flow from the inlet port. With use of the Boussinesq approximation, the dimensionless governing equations under steady-state condition are given by:

$$
\begin{aligned}
& \frac{\partial U}{\partial X}+\frac{\partial V}{\partial Y}=0 \\
& U \frac{\partial U}{\partial X}+V \frac{\partial U}{\partial Y}=-\frac{\partial P}{\partial X}+\frac{1}{R e}\left(\frac{\partial^{2} U}{\partial X^{2}}+\frac{\partial^{2} U}{\partial Y^{2}}\right) \\
& U \frac{\partial V}{\partial X}+V \frac{\partial V}{\partial Y}=-\frac{\partial P}{\partial Y}+\frac{1}{R e}\left(\frac{\partial^{2} V}{\partial X^{2}}+\frac{\partial^{2} V}{\partial Y^{2}}\right)+R i(\Theta+N C) \\
& U \frac{\partial \Theta}{\partial X}+V \frac{\partial \Theta}{\partial Y}=\frac{1}{\operatorname{RePr}}\left(\frac{\partial^{2} \Theta}{\partial X^{2}}+\frac{\partial^{2} \Theta}{\partial Y^{2}}\right) \\
& U \frac{\partial C}{\partial X}+V \frac{\partial C}{\partial Y}=\frac{1}{R e P r L e}\left(\frac{\partial^{2} C}{\partial X^{2}}+\frac{\partial^{2} C}{\partial Y^{2}}\right)
\end{aligned}
$$

where the dimensionless variables are

$$
\begin{gathered}
(X, Y)=\frac{(x, y)}{L},(U, V)=\frac{(u, v)}{u_{i}}, P=\frac{p}{\rho u_{i}^{2}} \\
\Theta=\frac{T-T_{i}}{\Delta T}, \Delta T=\frac{q L}{k}, C=\frac{c-c_{i}}{c_{h}-c_{i}}
\end{gathered}
$$

and the dimensionless parameters are Reynolds number, Grashof number, Richardson number, Prandtl number, Lewis number and the buoyancy ratio and they are defined as follows:

$$
\begin{aligned}
& R e=\frac{u_{i} L}{v}, G r=\frac{g \beta_{T} \Delta T L^{3}}{v^{2}}, R i=\frac{G r}{R e^{2}} \\
& \operatorname{Pr}=\frac{v}{\alpha}, L e=\frac{\alpha}{D} \text { and } N=\frac{\beta_{c}\left(c_{h}-c_{i}\right)}{\beta_{T} \Delta T}
\end{aligned}
$$

The buoyancy ratio measures the relative importance of solute and thermal diffusion in creating the density difference to drive the flow. It is clear that $\mathrm{N}$ is zero for pure thermally driven flows and infinity for pure solute driven flows. In the present study, the thermal expansion coefficient $\beta_{T}$ is positive for the density of the air mixture decreases as the temperature increases, and also $\beta_{c}>0$ for the assumption that the polluted gas indoors is lighter than the air and thus the concentration of the air mixture decreases as the polluted gas increases, and hence $N>0$.

The appropriate boundary conditions for the present problem are:

a) At the inlet: $U=1, V=\Theta=C=0$

b) At the outlet: $\frac{\partial U}{\partial X}=V=\frac{\partial \Theta}{\partial X}=\frac{\partial C}{\partial X}=0$ c) Walls: $U=V=0 ; \frac{\partial \Theta}{\partial Y}=-1, C=1$ for heat and contaminant sources and $\frac{\partial \Theta}{\partial n}=\frac{\partial C}{\partial n}=0$ elsewhere.

The heat and mass transfer rates on the surfaces of heat and contaminant sources are described by the average Nusselt and Sherwood numbers, respectively as follows

$$
\begin{gathered}
N u=\left.\frac{L}{L_{s}} \int_{0}^{L_{s} / L} \frac{1}{\Theta}\right|_{Y=0} d X \\
S h=\frac{L}{L_{S}} \int_{0}^{L_{s} / L}-\left.\left(\frac{\partial C}{\partial Y}\right)\right|_{Y=0} d X
\end{gathered}
$$

\subsection{Numerical Procedure}

The numerical procedure used to solve the governing equations for the present work is based on the Galerkin weighted residual method of finite element formulation. The application of this technique is well documented by Zienkiewicz and Taylor [24]. The nonlinear parametric solution technique is chosen to solve the governing equations. This approach will result in substantially fast convergence assurance. A nonuniform triangular mesh arrangement is implemented in the present investigation especially near the corrugated walls to capture the rapid changes in the dependent variables. To test and assess the grid independence of the present solution, several numerical runs are performed for higher Richardson numbers as shown in Table 1. These results reveals that a nonuniform spaced grid approximately 42962 nodes for the solution domain is adequate to describe correctly the flow and heat and mass transfer processes inside the cavity. The code used in the present work has been validated for many previously published works $[16,17,23]$.

Table 1: Comparison of the Results for Various Grid Dimensions of Bottom exit configuration $(R i=1.0)$

\begin{tabular}{ccc}
\hline Nodes (Elements) & $\mathrm{Nu}$ & $\mathrm{Sh}$ \\
\hline $18465(1960)$ & 7.952 & 3.555 \\
$26455(2900)$ & 7.957 & 3.561 \\
$31334(3474)$ & 7.961 & 3.564 \\
$42962(4842)$ & 7.968 & 3.571 \\
$56375(6420)$ & 7.969 & 3.57 \\
\hline
\end{tabular}

\section{Results and Discussion}

In the present study, the size configurations of the vented cavity, the heat and contaminant sources and the inlet and outlet are kept constant as $H / L=$ $1.0, L s / L=0.5$ and $d / L=0.1$. Reynolds number, 
Prandtl number, Lewis number and the buoyancy ratio are kept fixed at 100, 0.7, 1 and 1 respectively. Three different locations (bottom, middle and top) of the outlet port are considered in the present investigation. Moreover, main attention is then focused on the effects of the governing parameter, Richardson number on the indoor air mixed convection. The range of Richardson number used for the simulations is $0.1 \leq R i \leq 10$ and it is obtained by varying the Grashof number only. Now in the following section, a detailed description of mixed convection with heat and mass transfer in a vented cavity is given in terms of streamline, thermal and concentration contours for three different exit port configurations. In addition, the results for both average Nusselt and average Sherwood numbers at various conditions will be presented and discussed.

\subsection{Bottom Exit Configuration}

Figure 2 presents the effect of Richardson number on the streamline, isothermals and isoconcentration contours for bottom exit configuration. In this figure the effect of both thermal buoyancy force and solutal buoyancy force are equal. Therefore, the double diffusive flow is applicable. The streamlines describe the interaction of forced and natural convection under various convection regimes. To assess the influence of buoyancy effects on the mixed convection flow, the results of the limiting case of purely forced convection are also included in Figure 2. At $\operatorname{Re}=100$, for the lower $\mathrm{Ri}$ values, forced convection dominates the major flow from the inlet to the exit without much penetrating into the cavity. At $\mathrm{Ri}=0.1$, the bulk induced flow expands in the cavity resulting increase in potential energy. Heat is carried out merely by forced convection. A recirculating cell of low velocity is formed which occupies half of the cavity. It is of interest to note that both $\Theta$ and $C$ develop in a very similar way. This is simply because the Le and $\mathrm{N}$ in the gas flow is taken as unity. Careful inspection, however, discloses that the mass-fraction boundary layers develop a little more rapidly than the temperature boundary layers. This is simply due to the fact that the isoflux heating boundary condition is much different than the uniform isoconcentration contaminant source boundary condition. With increased dominance of natural convection at $\mathrm{Ri}=10$, the cold incoming air and the hot vortex start to mix up and carry the heat to the bulk of the cavity. Besides, an increase in the value of Ri, through an increase in Gr, leads to denser isothermal lines because of the increasing recirculation. Thus the isothermal lines concentrate at the heat source for $\mathrm{Ri}=10$ as shown in the last row of Figure 2.

Making a comparison of isoconcentration lines for various $\mathrm{Ri}$, no significant difference is found except that the dense isoconcentration lines at low $\mathrm{Ri}$ are shifted towards right exit corner. This forms a strong assisted flow for the species concentration, thereby faciliting mass transport out through the exit. There is hardly any distortion in the thermal and concentration fields until the buoyancy and inertia forces become equally dominant at $\mathrm{Ri}=1$. In fact, high Richardson number on the other hand decreases the boundary layer in the vicinity of right part of the bottom wall.

\subsection{Middle Exit Configuration}

Similar representations of the fluid, heat and mass flow behavior inside a vented cavity with middle exit configuration are displayed in Figure 3. The basic flow structure in the absence of the free convection effect for $\mathrm{Ri}=0.1$ is presented in the top of the first column of Figure 3. The corresponding isothermal and isoconcentration contours result from combined effects of conduction and forced convection. At $\mathrm{Ri}=0.1$ while the induced flow enters into cavity through small inlet area, sudden expansion of the bulk fluid is occurred due to pressure rise into the cavity. Thus the bulk fluid occupies most of the part of the cavity. A medium vortex of very low speed appears at the left top corner of the cavity. Here heat is carried out by conduction due to kinematic energy drop in the bulk fluid, less mass in contact with the bottom discrete source and thermally saturated fluid in the cavity. In line with the wall heating and liquid film evaporation, the temperature and mass fraction in the right portion of the heat and contaminant source increase gradually as the pollutant air goes upward exit port rapidly. It is also clear in Figure 3 that relative to the pure forced convection results, the developments of temperature and concentration profiles are slower for the mixed convection case. This is simply due to the fact that the flow near the heated wall is continuously accelerated by the transverse buoyancy effects along the vertical direction, enhancing the heat and mass transfer in the horizontally and hence, decreasing the advancement of heat and mass transfer in the transverse directions.

\subsection{Top Exit Configuration}

Streamlines, isothermal and isoconcentration contours illustrating the effect of Richardson number are presented in Figure 4 for top exit configuration. For very low $\mathrm{Ri}$, the bulk induced fluid flow diagonally from the inlet to the exit and a pocket of fluid is formed at the upper part of the left insulated wall. Thus conduction and forced convection effects are dominant. For $\mathrm{Ri}=1$, it can be seen from Figure 4 that the natural convection effect is present but remains relatively weak since open lines characterizing the imposed flow are still dominant. Further increase of Ri gradually develops the recirculating cell, located at the left top corner of the cavity and leads to a large change in the streamline structure. For $\mathrm{Ri}=10$, the upper recirculation zone spreads and thereby squeezes the induced flow path resulting almost same kinetic energy 

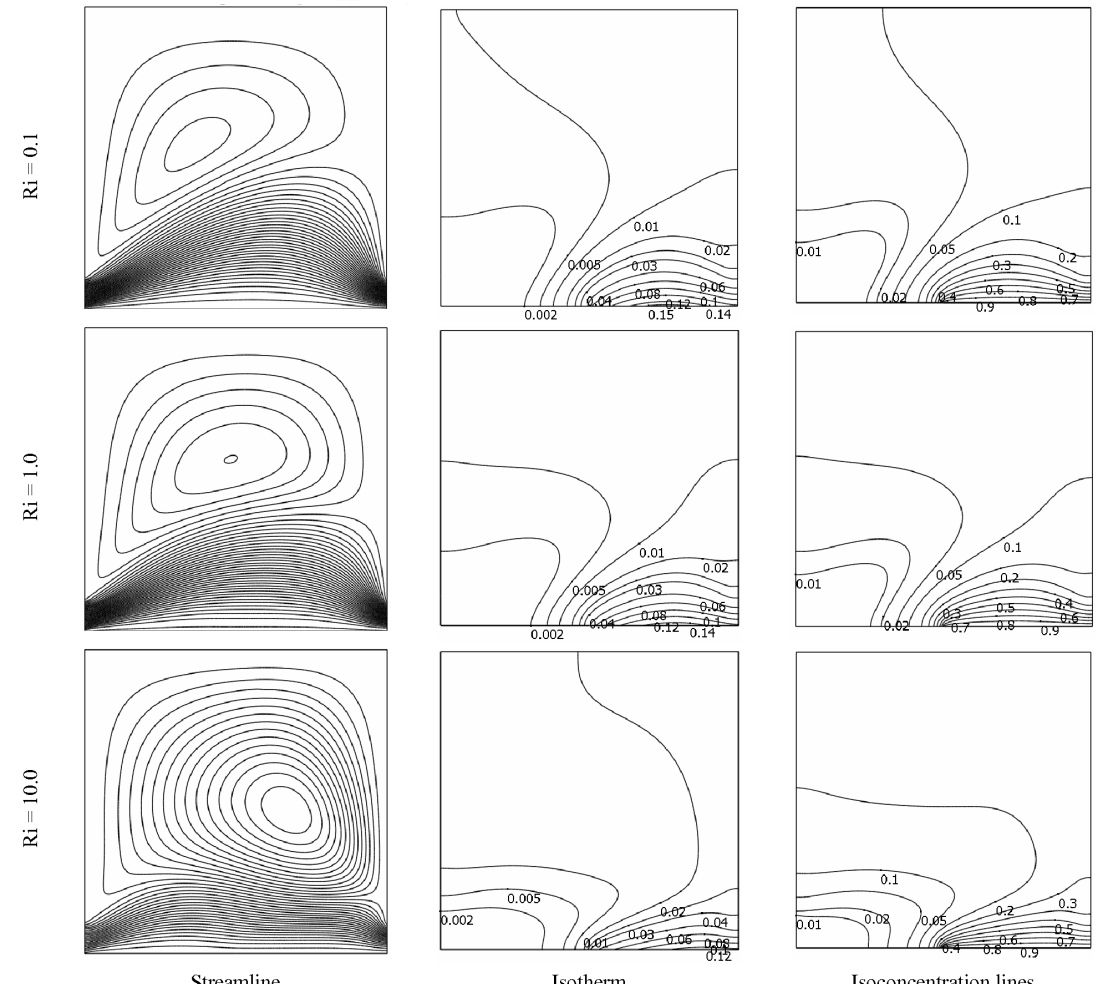

Figure 2: Streamline, isotherm and isoconcentration line for different Richardson numbers at the bottom exit configuration
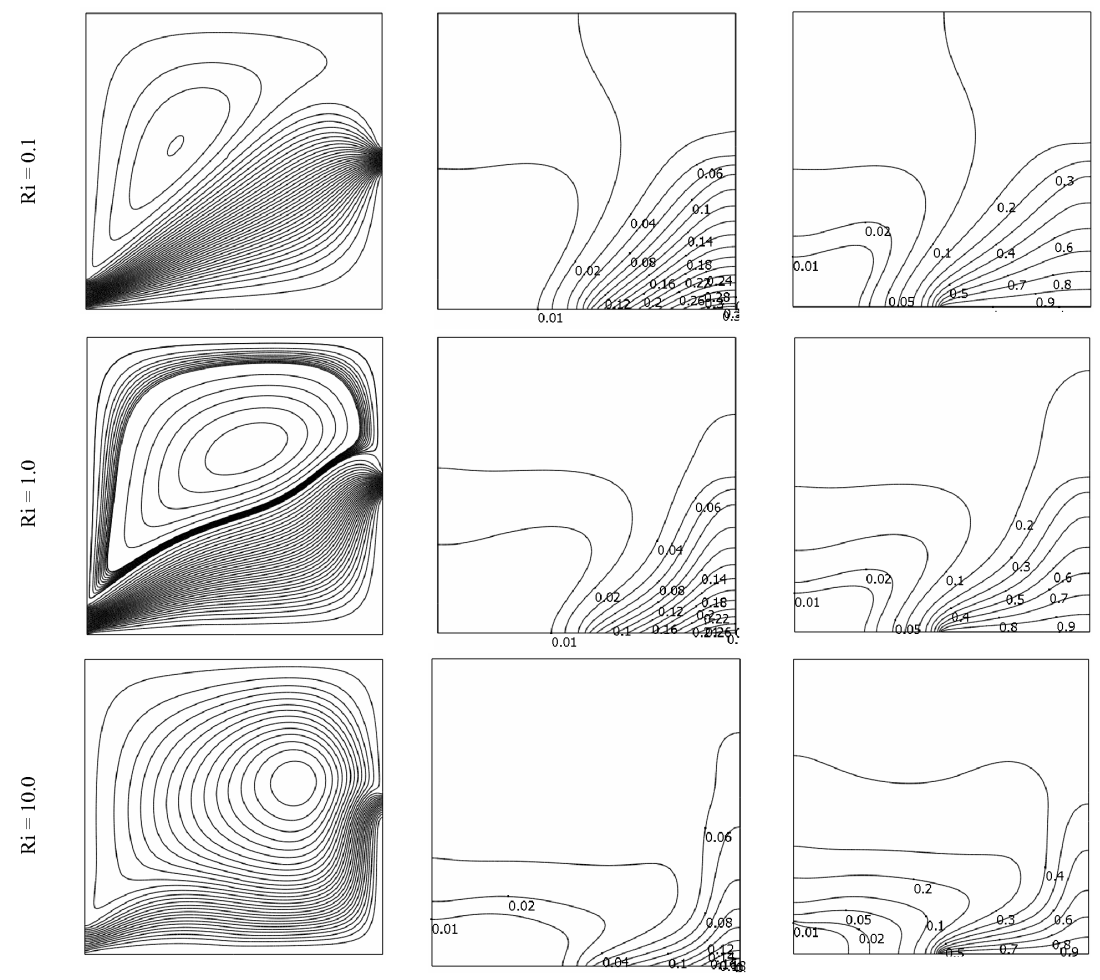

Streamline

Isoconcentration lines

Figure 3: Streamline, isotherm and isoconcentration line for different Richardson numbers at the middle exit configuration 

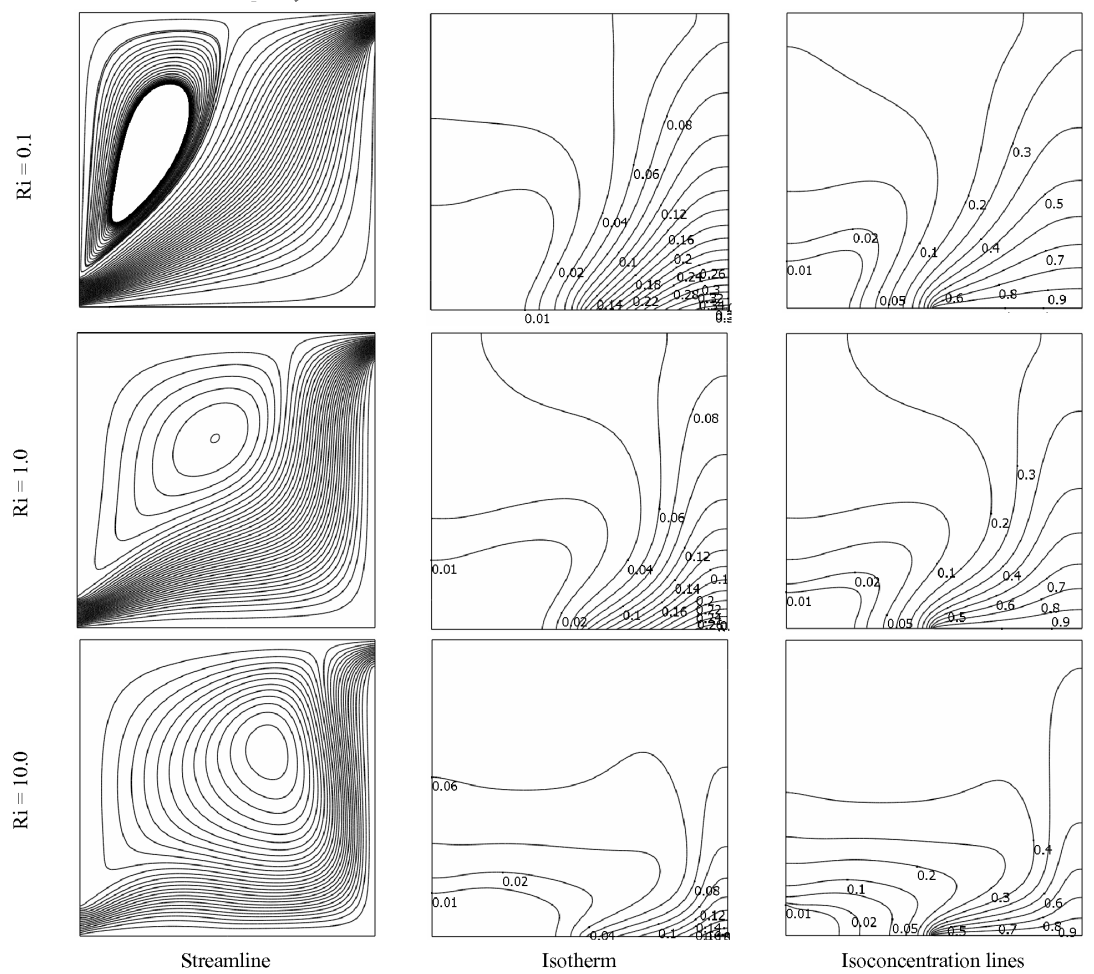

Figure 4: Streamline, isotherm and isoconcentration line for different Richardson numbers at the middle exit configuration

in the bulk induced flow as that of the inlet section. Convection heat transfer introduces with the growth of the recirculating cell resulting the faster removal of heat and mass from the heat and contaminant source. It must be noticed that when the buoyancy force increases with the increase of heat flux and concentration gradient, the recirculation zone begins to develop by absorbing the thermal energy through the induced forced flow. Thereby the squeezed induced flow covers the whole part of the heat and contaminant source at higher Ri. Similarly, the effect of natural convection on the temperature and concentration distribution is characterized by the displacement of the isotherms and isoconcentration front throughout the cavity. But, since the induced flow sweeps over the heat and contaminant level at the right lower corner of the cavity decrease indicating better heat and mass transfer. As $\mathrm{Ri}$ increases, nonlinearity of the isotherms and isoconcentration lines become higher and plume formation is profound, indicating the well established natural convection double diffusive flow.

\subsection{Heat and Mass Transfer Characteristics}

The effect of Richardson number on the average Nusselt number and average Sherwood number for different exit configurations is shown in Figures 5 and 6 respectively. A similarity of average Nusselt and Sherwood number is found between top and middle exit configurations. As Ri increases, average Nus-

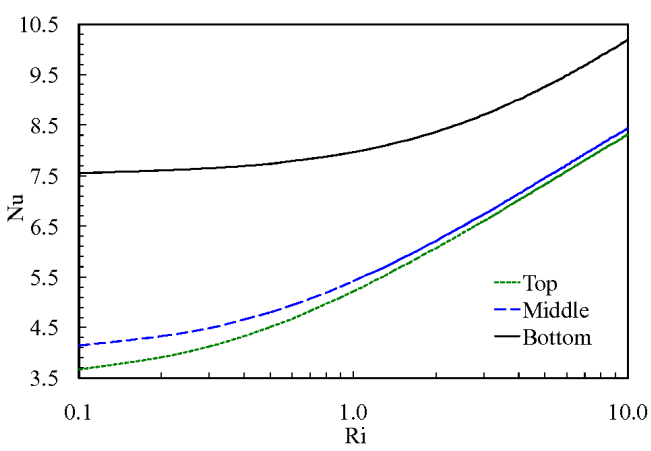

Figure 5: Average Nusselt number variation with Richardson number for different exit configurations

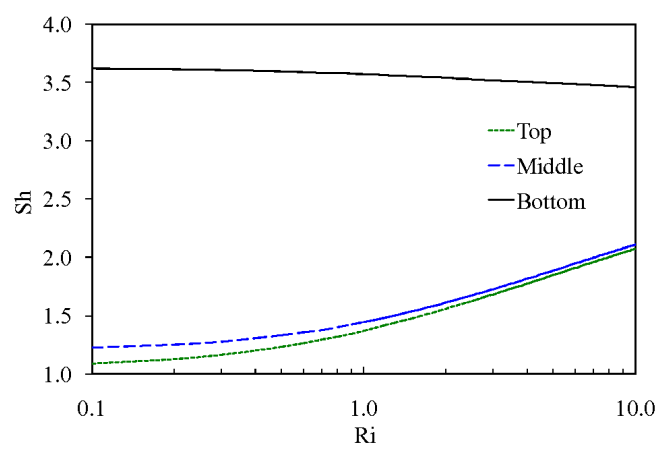

Figure 6: Average Sherwood number variation with Richardson number for different exit configurations 
selt number increases gradually for all configurations. Average Sherwood number indicates similar trend of mass transfer rate with the variation of Richardson number in all configuration except bottom exit port orientation. However, maximum average Nusselt and Sherwood number is obtained, without the effect of $\mathrm{Ri}$, in bottom exit configuration. This scenario of heat and mass transfer is occurred because the induced forced flow passes over the heat and contaminant source all the time. Thus heat and mass transfer is enhanced by forced convection rather than natural convection.

\section{Nomenclature}

$\alpha \quad$ thermal diffusivity

$\beta \quad$ expansion coefficient

$v \quad$ kinematic viscosity

$\rho$ density

$\Theta \quad$ nondimensional temperature

$C$ nondimensional concentration

$c$ concentration

$D \quad$ mass diffusivity

$d \quad$ size of inlet and outlet

$g \quad$ gravitational acceleration

Gr Grashof number

$H \quad$ height of the cavity

$k \quad$ thermal conductivity

$L \quad$ width of the cavity

Le Lewis number

$N \quad$ buoyancy ratio

$n \quad$ outward normal direction

$\mathrm{Nu}$ average Nusselt number

$P \quad$ nondimesional pressure

$p \quad$ pressure

$\operatorname{Pr} \quad$ Prandtl number

$q \quad$ heat flux

Re Reynolds number

$R i \quad$ Richardson number

$S h \quad$ average Sherwood number

$T$ temperature

$U, V$ nondimensional velocity components

$u, v \quad$ velocity components

$X, Y$ nondimensional coordinate

$x, y \quad$ Cartesian coordinate

\section{References}

[1] Howard-Reed C, Wallace L and Emmerich S, Effect of ventilation systems and air filters on decay rates of particles produced by indoor sources in an occupied townhouse, Atmospheric Environment, 2003. 37(38):pp. 5295-5306. doi : 10.1016/j.atmosenv.2003.09.012

[2] Carrer P, Maroni M, Alcini D and Cavallo D, Allergens in indoor air: environmental assessment and health effects, The Science of the Total Environment, 2001. 270(1-3):pp. 33-42. doi : 10.1016/S0048-9697(00)00791-9
[3] Papanicolaou E and Jaluria Y, Mixed convection from an isolated heat source in a rectangular enclosure, Numerical Heat Transfer, Part A: Applications, 1990. 29(4):pp. 427-461. doi:10.1080/10407789008944802

[4] Papanicolaou E and Jaluria Y, Transition to a periodic regime in mixed convection in a square cavity, Journal of Fluid Mechanics, 1992. 239:pp. 489-509. doi:10.1017/ S0022112092004506

[5] Papanicolaou E and Jaluria Y, Mixed convection from a localized heat source in a cavity with conducting walls: a numerical study, Numerical Heat Transfer, Part A: Applications, 1993. 23(4):pp. 463-484. doi:10.1080/ 10407789308913683

[6] Papanicolaou E and Jaluria Y, Mixed convection from simulated electronic components at varying relative positions in a cavity, Journal of Heat Transfer, 1994. 116(4):pp. 960-970. doi: $10.1115 / 1.2911472$

[7] Papanicolaou E and Jaluria Y, Computation of Turbulent Flow in Mixed Convection in a Cavity With a Localized Heat Source, Journal of Heat Transfer, 1995. 117(3):pp. 649-658. doi: $10.1115 / 1.2822626$

[8] Angirasa D, Mixed convection in a vented enclosure with an isothermal vertical surface, Fluid Dynamics Research, 2000. 26(4):pp. 219-233. doi:10.1016/S0169-5983(99) 00024-6

[9] Raji A and Hasnaoui M, Corrlations en convection mixte dans des cavits ventiles, Revue Gnrale de Thermique, 1998. 37(10):pp. 874-884. doi:10.1016/S0035-3159(98) 80012-3

[10] Raji A and Hasnaoui M, Mixed Convection Heat Transfer in a Rectangular Cavity Ventilated and Heated From the Side, Numerical Heat Transfer, Part A: Applications, 1998. 33(5):pp. 533-548. doi:10.1080/10407789808913953

[11] Raji A and Hasnaoui M, Mixed convection heat transfer in ventilated cavities with opposing and assisting flows, Engineering Computations, 2000. 17(5):pp. 556-572. doi: 10 . $1108 / 02644400010339770$

[12] Raji A and Hasnaoui M, Combined mixed convection and radiation in ventilated cavities, Engineering Computations, 2001. 18(7):pp. 922-949. doi:10.1108/ EUM0000000006212

[13] Hsu TH and Ang SGW, Mixed Convection in a Rectangular Enclosure with Discrete Heat Sources, Numerical Heat Transfer, Part A: Applications, 2000. 38(6):pp. 627-652. doi: 10.1080/104077800750021170

[14] Omri A and Nasrallah SB, Control Volume Finite Element Numerical Simulation of Mixed Convection in an Air-Cooled Cavity, Numerical Heat Transfer, Part A: Applications, 1999. 36(6):pp. 615-637. doi:10.1080/104077899274606

[15] Singh S and Sharif MAR, Mixed Convective Cooling of a Rectangular Cavity with Inlet and Exit Openings on Differentially Heated Side Walls, Numerical Heat Transfer, Part A: Applications, 2003. 44(3):pp. 233-253. doi:10.1080/ 716100509

[16] Saha S, Islam M, Ali M, Mamun M and Islam M, Effect of inlet and outlet locations on transverse mixed convection inside a vented enclosure, Journal of Mechanical Engineering, IEB, 2006. 36:pp. 27-37. doi:10.3329/jme.v36i0.808

[17] Saha S, Mamun M, Hossain M and Islam A, Mixed convection in an enclosure with different inlet and exit configurations, Journal of Applied Fluid Mechanics, 2008. 1(1):pp. 78-93

[18] Yan WM, Turbulent Mixed Convection Heat and Mass Transfer in a Wetted Channel, Journal of Heat Transfer, 1995. 117(1):pp. 229-233. doi : 10.1115/1.2822311

[19] Yan W, Combined buoyancy effects of thermal and mass diffusion on laminar forced convection in horizontal rectangular ducts, International Journal of Heat and Mass Transfer, 1996. 39(7):pp. 1479-1488. doi : 10.1016/0017-9310(95) 00227-8

[20] Lee K, Tsai H and Yan W, Mixed convection heat and mass transfer in vertical rectangular ducts, International Journal of 
Heat and Mass Transfer, 1997. 40(7):pp. 1621-1631. doi: 10.1016/S0017-9310 (96) 00192-5

[21] Alimi SE, Orfi J and Nasrallah SB, Buoyancy effects on mixed convection heat and mass transfer in a duct with sudden expansions, Heat and Mass Transfer, 2005. 41(6):pp. 559-567. doi:10.1007/s00231-004-0566-9

[22] Brown N and Lai F, Correlations for combined heat and mass transfer from an open cavity in a horizontal channel, International Communications in Heat and Mass Transfer, 2005. 32(8):pp. 1000-1008. doi:10.1016/j . icheatmasstransfer.2004.10.029

[23] Deng Q, Zhou J, Mei C and Shen Y, Fluid, heat and contaminant transport structures of laminar doublediffusive mixed convection in a two-dimensional ventilated enclosure, International Journal of Heat and Mass Transfer, 2004. 47(24):pp. 5257-5269. doi:10.1016/j. ijheatmasstransfer.2004.06.025

[24] Zienkiewicz $\mathrm{O}$ and Taylor R, The finite element method, Butterworth-Heinemann, 5th edition, 2000 